\title{
CONTEMPORARY MARKETING IN PHARMACY WITH THE FOCUS ON THE E- PHARMACY CONCEPT
}

\section{Dejana Ignjatović*1 Milenko Stanić ${ }^{2}$}

${ }^{1} \mathrm{PhD}$ candidate,Sinergija University, Bijeljina, Republic of Srpska ${ }^{2}$ Sinergija University, Bijeljina, Republic of Srpska

\section{Correspondence:}

Dejana Ignjatović

e-mail:

\begin{abstract}
:
The role of pharmacies has changed during the last decades of the 20th century within both the societal and medical spheres. From a place manufacturing medicine, to procurement and distribution of medicine, pharmacies have becoame modern medical facilities that participate in the medical system and retail pharmaceutical market. The duality of the role of pharmacy requires adjustments to the demands of healthcare policies and contemporary market principles. The implementation of contemporary business practices, such as marketing, was mostly absent, until recently. This research focuses on the use of internet for pharmaceutical marketing and the possible application of online pharmacies in the Republic of Srpska. Pharmaceutical workers, the respondents of the questionnaire, point to the possibilities that the implementation of online business presents all the strengths and weaknesses of such a manner of operation. From this, it is concluded that the implementation of electronic pharmacies would lead to the improvement of economic results for pharmaceutical establishments within the Republic of Srpska and Bosnia and Herzegovina.
\end{abstract}

\section{Keywords:}

pharmacy, online pharmacy, marketing

\section{INTRODUCTION}

Pharmaceutical marketing is a very intensive discipline which encompasses both general and specific knowledge of marketing and business activities connected to the product/service in the sphere of medicine, therapy, improvement of the health of patients/citizens/buyers, with profits going to the society and organizations which provide the product/service (economy and healthcare).

With the adequate infrastructure for e-business, technology is a second major prerequisite for the realization of efficient e-business activities and operations in pharmacy.

Electronic pharmacy can be defined as a process of buying, selling, transfer or exchange of pharmaceutical products, services or information on a computer network, including the Internet. (Balaban, 2009).

Online distribution of medicine is becoming globally present, and its results will be quantifiable in the coming decades. Current experience points to the lack of professional oversight of the distribution of "for health" products, which has led to numerous life threatening consequences. Nevertheless, the trend towards more liberal markets has made an impact on the pharmaceutical market as well. In Bosnia and Herzegovina, only pharmacies have the license to sell medicine.

The use of digital marketing and modern, electronic forms of business in pharmacy would greatly increase the rate of distribution of pharmaceutical products in pharmacies across the Republic of Srpska.

The aim of this research is, on the basis of domestic and foreign references and the discoveries that came through them, to inform the public about different 
technologies and models of e-trade in pharmacy, and to determine the importance of electronic marketing and the implementation of electronic models of business for the advancement of pharmaceutical business.

The social aim of this research is to offer new information and discoveries to all those who are employed in pharmaceutics and wish to involve themselves in electronic trade and marketing, so that their pharmacy could be competitive on the market.

The results of the research will confirm the importance of new technologies in pharmaceutics for the improvement of business transactions and making pharmaceutical products more available.

The survey was conducted on the territory of the Republic of Srpska September, 2019. The information about the attitude of employees in the pharmaceutical business were collected using a questionnaire in one hundred pharmacies in the territory of the Republic of Srpska, where the respondents had the ability to state their views on the importance of implementing forms of electronic business in pharmacy.

The research was conducted using a survey questionnaire. During the research, the methods of synthesis, analysis and description were used. The research was comprised of a stratified sample of one hundred respondents on the territory of the Republika Republic of Srpska, and was conducted during the month ofin September, 2019.

It is expected that the research will confirm the hypothesis, to prove that the electronic business method would improve the work of pharmacies and that this method would make the products more available to the general public which would lead to the increase in profit.

The research is divided into five parts. After the introduction in the first part, the second part of the work talks about the importance of electronic marketing and electronic trade in pharmacy. The third part presents the results of the research, while the fourth part discuses the results. The fifth part provides the conclusion.

\section{THE IMPORTANCE OF ELECTRONIC MARKETING AND ELECTRONIC TRADE IN PHARMACY}

As stated in the previous part, pharmaceutical marketing is an intense discipline that encompasses both general and specific knowledge of marketing and business activities relating to products/services in the sphere of medication, therapy and the betterment of health for the patient/ citizen/consumer, while all along making a profit for the society and organization which provides the products/ services (economy and healthcare).

Pharmaceutical business is of general and specific social interest, because it directly contributes to the betterment and protection of people's health. It encompasses production, control, distribution, prescription and sale of pharmaceutical products, but it also offers different healthcare services that are aimed at bettering the quality of lives for the general public.

Accordingly, pharmaceutical marketing encompasses both general and specific knowledge related to products of services in the spheres of medicine, therapy and health betterment. Thus, the concepts of pharmaceutical products marketing and pharmaceutical services marketing are regarded as separate, when in reality they are indivisible.

Internet marketing cannot replace conventional forms of marketing, but the Internet has a number of advantages on the more conventional forms of media. (Kostić, 2003).

Advertisements on the internet are the simplest way of promoting services or products. The Iinternet is a global network, so it allows for simple presentation of products for a wide audience.

The Internet presents many unique advantages, and one of them is certainly the easiest and most simplified distribution of information to a wide range of consumers. (maag-projekt.com, n.d.).

The advantages of Internet marketing over classical forms are numerous. Internet marketing is direct marketing. It is used to directly communicate with clients and to enter every home. And unlike other forms of direct marketing, Internet marketing is also interactive.. Internet users usually have a way to connect with the advertiser immediately, while the advertiser can continuously monitor the effects of their marketing campaign. Using the Internet as a medium, a target group can be chosen and designated to be the focus of the marketing, thus a greater efficiency and cost reduction is achieved. (www. internetmarketing.ba, n.d.).

The efficiency of an Internet advertisement is measurable, because it can be determined how many times the advertisement was seen, and how many times the web presentation was visited. There are two methods of tracking those counts: Web centric (counters on the site) and User centric. Online business provides the best ways of quantifying marketing efficiency, regarding the number of views of advertisements, number of clicks, subscriptions to newsletter, likes and others. Furthermore, it is possible to track the movement of consumers during their time on the web page. All theseis information increases the ability to analyze the behavior of consumers, which in turn increases the quality of the offer and the advertisement campaign.

The Iinternet can not only display texts and graphics, but also audio and video contents. The Iinternet is becoming an integral part of MEDIA MIX, so new forms of advertisements are becoming available: animated banners, logo sponsors and 3D animations. (Latinović, 2007). 


\section{Pharmaceutical products marketing}

Pharmaceutical marketing is specific because medicine and medical products have a specific use and are not available to everyone, but only to those who have a doctor's prescription or are advised by their pharmacist. At the same time, these products are responsible for people's health, thus they are subject to a strict and special legislation on their way to the market, starting from regulations during manufacturing, quality control, distribution, a premarketing phase, registration procedure - marketing license to the post-marketing phase of tracking the medicine.

Advertising OTC medicine should encourage rational use of the medicine, presenting it objectively and without the overemphasizing its properties, and should not be wrong or misinforming. Here, OTC products are available in public pharmacies, so the pharmacists are the primary promoters of this kind of medicine to the population that is asking them for advice and medicine for milder aliments. In European countries and the rest of the world, however, this type of medicine is allowed to be sold outside of pharmacies, in places such as supermarkets or gas stations, so they are available to the general population without any oversight. Medicine must stay in pharmacies, even if it is a herbal medicine, or a multivitamin products in effervescent pills (it is not a substance like juice, that can be drank without limit), because only highly educated individuals, such as the staff of pharmacies, can provide the public with the correct information as to how, how long and in what combination with other products can the medicine be used. That cannot be done by any advertisement or any seller in stores. When OTC products are advertised via electronic media, short videos are used awith a brief story about the medicine are shown, appropriate slogans are used, and people with a common cold and sneezing are shown to be getting better after taking the medicine (e.g. Aspirin plus $\mathrm{C}^{\otimes}$ Bayer Pharma, Andol $\mathrm{C}^{\circledast}$ Pliva, Coldrex ${ }^{\circledast}$ Glaxo Smith Kline on television), or an appropriate slogan is used on the radio (e.g. puts out the fire in the stomach, Gelusil-Lac ${ }^{\oplus}$, Hemofarm). The end of every video comes with a warning that the patient should consult their doctor or pharmacist regarding more information, indications and side effects. Marketing OTC is also done in daily papers, where a pharmaceutical company takes out an advertisement in the papers and puts a picture of the product with an appropriate slogan or a short text about indications and the proper use of the product, and where it is available. One such example is a constant advertisement of Bosnalek in Glas Srpske, which advertises its products Rhinostop tablets and syrup (against common cold, sneezing) and Royal jelly - a product based on royal jelly for a strengthening an immune system. They also advertise the product Ranibos ${ }^{\oplus} 75 \mathrm{mg}$ tablets. These examples are noted, not as an advertisement for certain pharmaceutical companies, but as a real life examples that are most common in media, and this trend, where an actual example is needed, will continue. Unlike OTC products, medicine that is given only with a prescription are not allowed to be advertised through public media, but are instead advertised through brochures and presentation in healthcare institutions, expert meetings, symposiums, congresses, professional literature and publications. These are used as a mean of informing healthcare workers about these products, so that they may recommend them to patients/general population. The choice of medicine should be made by a joint decision of a doctor and a pharmacist, not the patient alone. (Tasić, 2002).

\section{Pharmaceutical services marketing}

A service is an act or a deed that one side can offer to another, which is totally intangible and does not result in owning anything. The production of a service may or may not be linked to a physical product. Services can, in lesser or greater part, make up a company's offer on the market. There are five categories of offers:

- Completely tangible good - the offer consists entirely of a tangible good. Services do not come with the product (buying of consumer goods)

- Tangible good with accompanying services - the offer consists of a tangible product with one or more services whose primary goal is the increase of its usable value (giving medicine with a prescription)

- Hybrid good - the offer consists of a product and a service in equal parts (self-medication, the sale of medicine without prescription)

- Majority service with accompanying goods and services - the offer consists of a main service, coupled with additional services and/or supporting products (e.g. obesity counseling)

- Total service - the offer consists entirely of services (turnon reports, blood pressure measuring, the exploitation of databases, etc.)

In case of marketing material products, the consumer buys the product and goes home or some other place to use it, whereas with service marketing, the consumer of the service stays in contact with the provider of the service for its duration, starting from its creation to its use, during which time it is in the interest of both sides to use it in such a way to stay in the contact for as long as possible.

There are multiple types of services, the most prominent ones being:

- Services which depend on human technical factors

- Non-expert and expert services

- Services dependent or independent from the product 
- Services whose generation requires strategic decisions of a great number of participants

- Services that bring profit in the long term or ones that are chargeable momentarily

- Services intended to create the company's image

- Innovative services

Pharmaceutical services are primarily provided in public pharmacies, hospital pharmacies, hospital wards, clinical-biochemical laboratories, but also in other healthcare, commercial, scientific and education institutions.

\section{Pharmaceutical marketing}

With the advent of a great number of medicine and other pharmaceutical products, there is an increase of negative side effects due to inadequate prescribing and incorrect use of medicine (resistance to antibiotics, complicated infections, side effects, etc.), which requires new skills and knowledge from pharmacists. Aside from pharmaceutical knowledge, pharmacists of the 21 st century need to master communication skills, management and leadership, which will allow them to offer the complete pharmaceutical service which involves the prevention of negative side effects of medicine, prevention of medicineon-medicine and medicine-on-food interactions, and other healthcare measures that contribute to the preservation of health. At the same time, service activities that unfold within pharmacies (making medicine and distribution of pharmaceutical products) should be supplemented with good marketing programs which include:

- Teamwork of pharmacists and other providers of primary healthcare

- Counseling about the use of non-healthcare measures (e.g. diet plan for hypertension), auxiliary products (dietary products) and self-treatment

- Increased activity in the post-marketing period with the goal to find any side effects and to take patients' complaints into consideration (unclear instructions, inadequate packaging, etc.)

- Pharmacies should be the best information centre about medication (for both healthcare institutions and patients) and promoters of campaigns (against smoking, hypertension, alcoholism, drug abuse, AIDS, etc.)

- Offering preventive diagnostics (measuring of TA, TM, blood sugar, cholesterol, etc.)

- New pharmacy ambient (no glass window on the counter, area for confidential discussion, easily accessible health related educational material (brochures, leaflets, boards, Iinternet, sites, e-mail contacts, polite staff, etc.)

\section{The role of Internet in pharmaceutical marketing}

In the last few years the Iinternet has become an important medium for the transfer and exchange of information and a powerful tool of communication. Researches show that nearly half of its users search health related topics, and the information that they find greatly impacts their decisions about future treatments. Modern terminology often uses the term virtual, which means an illusion of something that might be real. In IT terms, virtual means a specific multimedia Internet based environment that allows interaction between people as well as between computers. This new model of communication allows for communication between customers, customers and companies as well as between companies. Buyers and sellers are directly connected. Considering the previously stated, the Internet can completely change the way companies communicate with their clients, and at the same time, the consumers can quickly compare the offers and prices of products and services with different companies. For businesses, the most important part that the virtual (cyber) space offers is direct feedback from customers, the market in general, and the competition. The net presents a perfect testing ground for marketing research, recognition of customers' wishes, decision making, promotion, distribution of products and much more. One of the most interesting phenomena in pharmacy and healthcare are "on-line" (virtual) pharmacies, which originated in 1998, and in which customers can buy different medical products, including medicine. Taking into account previous trends, it is expected that electronic business and on-line pharmacies will have more influence on the medicine and healthcare services market. Virtual warehouses are a major advantage to electronic business, where there can be no shortage of medicine and other products, and which provide information to customers all the time. Also, electronic pharmacies provide the companies with an immediate contact and a direct route to customers. This way both the companies and the customers are at an advantage: pharmaceutical companies have greater control and profits, while customers are better informed and serviced. Nevertheless, this kind of business has certain problems linked to it, primarily with how to provide security and discretion of confidential information, and how to prevent illegal prescriptions and marketing of products of a suspicious quality. Even though the biggest barrier stated for this kind of business is the ignorance and lack of knowledge on the side of the customers, it is generally considered that the Internet-business is a positive thing and a lot of companies are planning to increase their investments in this area, so it is realistic to expect that the Internet will become an extremely important platform for the promotion of health and the distribution of healthcare services. 


\section{RESEARCH RESULTS}

The previous part discussed the marketing of pharmaceutical products and services, as well as the role of the Internet in pharmaceutical marketing. This serves as an adequate theoretical framework that precedes the research part that follows.

\section{General information about respondents}

Out of 100 respondents that answered the questions, $70 \%$ were female while $30 \%$ were male. As far as qualification is concerned, $61 \%$ of respondents have a university degree, while $39 \%$ have a high school degree.

\section{Result analysis and discussion}

From all of the respondents, $99 \%$ of them have heard about online purchasing, while $1 \%$ did not. This is illustrated in the following graph.

Graph 1 . The knowledge of sales of pharmaceutical products on the Internet

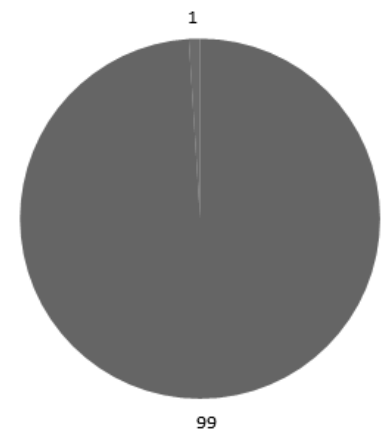

- Yes

- No

From all of the respondents, $13 \%$ said that that purchasing on the Iinternet is better, while $87 \%$ said that it is not.

Graph 2. The respondents' answers to the question whether purchasing pharmaceutical products online is better than the traditional way

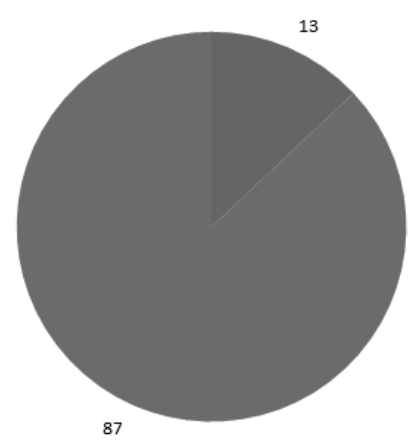

Metter

Worse
Answering the question whether they shop for regular non-pharmaceutical products online, $64 \%$ of respondents said that they do, while $36 \%$ said that they do not.

\section{Graph 3. The number of respondents that purchase products online}

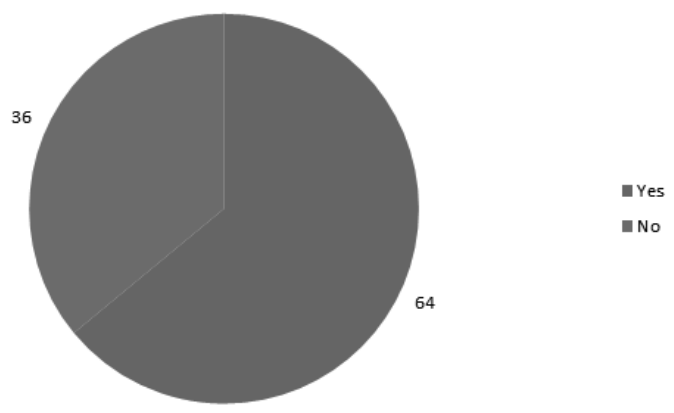

If it were possible, with regards to the current legislation in the Republic of Srpska, 65\% of respondents said that they would purchase medicine online, but only after consulting a pharmacist, while $24 \%$ said that they would not purchase medicine online.

Graph 4. Would the respondants purchase pharmaceutical products online

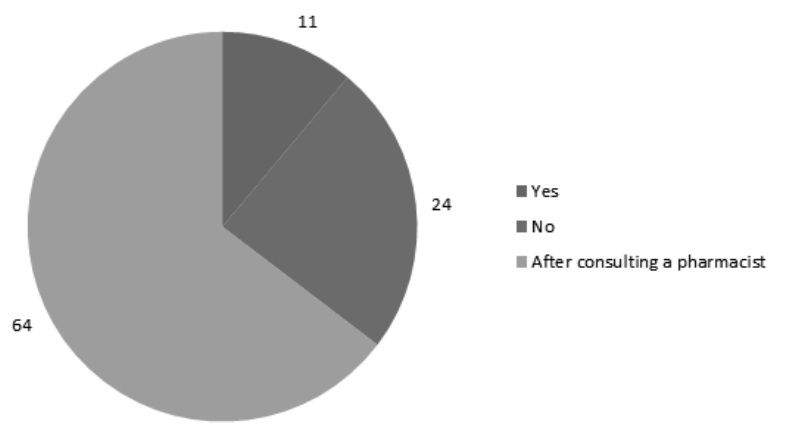

From all of the respondents, $18 \%$ said that they are completely unaware of the possibilities, advantages and disadvantages of online purchasing, $27 \%$ said that they are very informed, $26 \%$ said that they are averagely informed, while $29 \%$ said that they are not informed enough about the possibilities, advantages and disadvantages of online purchasing of pharmaceutical products. 
Graph 5. How well are the respondents informed about the possibilites, advanages and disadvantages of online purchasing of pharmaceutical products

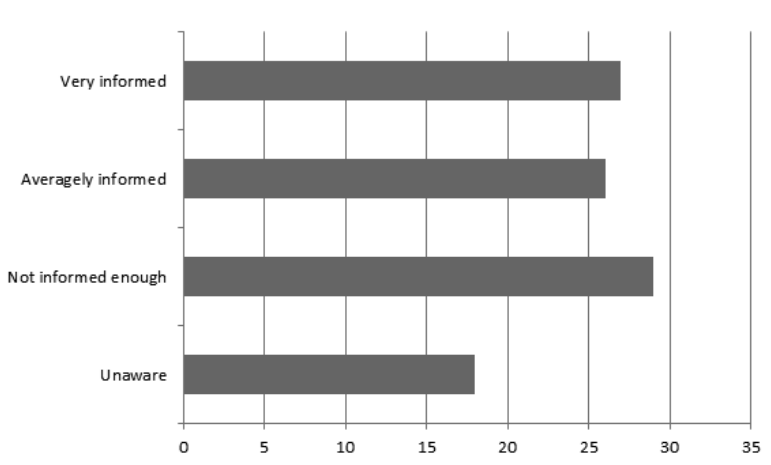

When asked about the main drawbacks of online purchasing of pharmaceutical products, $32 \%$ of the respondents said it is a lack of adequate security systems, $25 \%$ said the inability to get a refund, $24 \%$ said slow delivery, and $19 \%$ said the inability to check the quality of the products.

Graph 5. The main drawback of online purchasing of pharmaceutical products

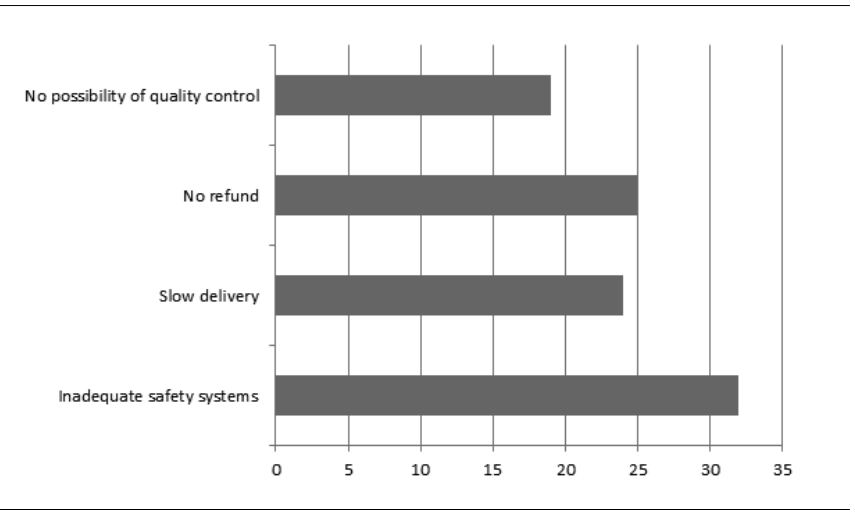

Linking the results with the hypothesis it can be concluded that the hypothesis is confirmed, because the results show that most of the respondents, who are pharmaceutical workers themselves, would purchase medicine on the Iinternet, rather than going to the pharmacy.

\section{DISCUSSION}

The importance of pharmaceutical marketing was elaborated on in the previous parts, where the specifics of marketing in this sphere and the importance of the Internet were discussed

Research shows a decrease in the number of active web locations of Internet pharmacies, the exchange of medical information is usually inefficient. Many network operators have been defined as illegal Internet pharmacies, but among them there were no legitimate Internet pharmacies. (Fitter, Bősze, \& Botz, 2013) In a research that dealtl with a cross-section study of 275 web locations in English, by using Google.com and AltaVista.com for "prescription drugs", it was concluded that Iinternet pharmacies that sell prescription medicine could be categorized into four groups: (1) legal pharmacies; (2) subscription pharmacies; (3) lifestyle pharmacies; (4) pharmacies without prescription. (Littlejohn, Baldacchino, Schifrano, \& Deluca, 2005). Evidence point to the fact that the customers are potentially exposed to risks when buying medicine online. Results also show that a great number of web locations sell medicine that they should not have, and that less than a quarter of all are regular online pharmacies. 80 web locations were ready to sell medication without prescription. (Liang, Mackay, \& Lovett, 2012). Answering the question whether they shop for regular non-pharmaceutical products online, $64 \%$ of respondents said that they do, while $36 \%$ said that they do not. If it were possible, with regards to the current legislation in the Republic of Srpska, 65\% of respondents said that they would buy medicine online, but only after consulting a pharmacist, while $24 \%$ said that they would not buy medicine online. From all of the respondents, $18 \%$ said that they are completely unaware of the possibilities, advantages and disadvantages of online purchasing, $27 \%$ said that they are very informed, $26 \%$ said that they are averagely informed, while $29 \%$ said that they are not informed enough about the possibilities, advantages and disadvantages of online purchasing of pharmaceutical products.

\section{CONCLUSION}

From all of the respondents, $13 \%$ said that that purchasing on the Internet is better, while $87 \%$ said that it is not. Linking the results with the hypothesis it can be concluded that the hypothesis is confirmed, because the results show that most of the respondents, who are pharmaceutical workers themselves, would buy medicine on the internet, rather than going to the pharmacy. Although, it is important to note that all of them consider that a consultation with a pharmacist is necessary.

\section{REFERENCES}

1) Balaban, N. (2009). Informacione tehnologije. Novi Sad: Ekonomski fakultet Subotica.

2) Fittler, A., Bősze, G., \& Botz, L. (2013). valuating Aspects of Online Medication Safety in Long-Term Follow-Up of 136 Internet Pharmacies: Illegal Rogue Online Pharmacies Flourish and Are Long-Lived. J Med Internet Res, 15(9), 199.

3) Judith, S., Carolyn, S., \& Rosemary, R. (2011). Selling drugs online: distribution-related legal/regulatory issues. International Marketing Review, 18(4).

4) Kostić, M. (2003). Internet marketing i online PR. Beograd: Veza d.o.o. 
5) Latinović, B. (2007). Marketing na internetu. INFOTEHJAHORINA, 6, 311-315.

6) Liang, B., Mackey, T., \& Lovett, K. (2012). Suspect online sellers and contraceptive access. Elsevier, 86(5).

7) Littlejohn, C., Baldacchino, A., Schifano, F., \& Deluca, P. (2005). Internet pharmacies and online prescription drug sales: a cross-sectional study, Drugs: Education. Prevention and Policy, 75-80.

8) Punoševac, M. (2011). Elektronska trgovina. Beograd: Poslovni fakultet Univerziteta Singidunum.

9) Tasić, L. (2002). Farmaceutski menadžment i marketing. Beograd: Nauka.

10) Downloaded 23. 092019 from maag-projekt.com: http:// www.maag-projekt.com/internet-marketing-web-internet-marketing

11) Downloaded 23. 092019 from www.internetmarketing.ba: http://www.internetmarketing.ba/internet_marketing.php

Survey questionnaire

\section{Greetings,}

This survey is anonymous and will be used for scientific use exclusively and for the writing of the research paper with the topic of "Modern marketing in pharmacy with a particular overview of the electronic pharmacy concept". Your opinion is very important to us, so we would like to thank you for your cooperation in advance.

General information

\begin{tabular}{cccc}
\hline 1. & \multicolumn{3}{c}{ Gender } \\
\hline \multicolumn{3}{c}{ Male } & Female \\
\hline 2. & \multicolumn{3}{c}{ Qualification } \\
\hline & High school & Collage & University \\
\hline 3. & Age \\
\hline & $20-35$ & $36-45$ & 46-or older \\
\hline
\end{tabular}

1) Have you heard about buying pharmaceutical products on the internet?

a) YES b) NO

2) Do you think that the purchasing on the internet is better that purchasing in pharmacies?
a) YES
b) $\mathrm{NO}$

3) Do you shop on the internet?

a) YES b) NO

4) If it was possible, would you buy medicine on the internet?
a) YES
b) ONLY A PHARMACIST$$
\text { c) } \mathrm{NO}
$$

5) Do you think you are well informed about the possibilities, advantages and disadvantages of online
a) I consider myself very informed
b) I consider myself averagely informed
c) I consider myself not informed enough
d) I consider myself not at all informed

6) What do you consider to be the main drawback of online purchasing of pharmaceutical products?
a) No possibility of quality control
b) No refund
c) Slow delivery
d) Inadequate safety systems 